\title{
Integrated reservoir characterization and fluid flow distribution of the Kaimiro Formation, Taranaki Basin, New Zealand
}

\author{
Mohamed Ragab Shalaby ${ }^{1,2}$ [D $\cdot$ Syamimi Hana Binti Sapri ${ }^{1} \cdot$ Md Aminul Islam $^{1}$
}

Received: 25 July 2020 / Accepted: 11 September 2020 / Published online: 22 September 2020

(c) The Author(s) 2020

\begin{abstract}
An integrated reservoir characterization study is achieved on the Early to Middle Miocene Kaimiro Formation in the Taranaki Basin, New Zealand, to identify the quality of the formation as a potential reservoir. The Kaimiro Formation is a section of the Kapuni Group in the Taranaki Basin, consisting mainly of sandstone and a range of coastal plain through shallow marine facies. Several methods were accomplished for this study: petrophysical evaluation, sedimentological and petrographical descriptions and well log analysis. Based on the petrophysical study, the Kaimiro Formation is interpreted to have several flow units ranges up to $15 \mu \mathrm{m}$. Higher RQI and FZI reflect potential reservoir, while the pore size and pore throat diameters (r35) are found to be within the range of macro- and megapores, on the contrary to macropores related to poor reservoir quality concentrated in Tui-1 well. This is in good agreement with other measurements that show the formation is exhibited to be a good promising reservoir as the formation comprises a good average porosity of $19.6 \%$ and a good average permeability of $879.45 \mathrm{mD}$. The sedimentological and petrographical studies display that several diagenetic features have been affecting the formation such as compaction, cementation, dissolution and the presence of authigenic clay minerals. Although these features commonly occur, the impact on the reservoir properties and quality is minor as primary and secondary pores are still observed within the Kaimiro sandstone. Moreover, well log analysis is also completed to further ensure the hydrocarbon potential of the formation through a qualitative and quantitative analysis. It has been confirmed that the Kaimiro Formation is a promising reservoir containing several flow units with higher possibility for storage capacity.
\end{abstract}

Keywords Kaimiro formation $\cdot$ Petrophysics $\cdot$ Petrography $\cdot$ Diagenetic features $\cdot$ Well logging $\cdot$ Reservoir quality

\section{Introduction}

The Taranaki Basin is the largest sedimentary basin in New Zealand, and it is situated on the North Island in the west coast of the country (Fig. 1) (Palmer 1985). The Taranaki Basin has a high quantity of commercial oil and gas reserves in New Zealand, covering an area of $100,000 \mathrm{~km}^{2}$ (King and Thrasher 1996). Furthermore, the reservoirs of this basin have been generating from the Paleocene to Pliocene ages, with the main petroleum reserves mostly found along the Paleocene shoreline with a broad northeast to southwest trending fairway and within the coastal plain Paleocene

Mohamed Ragab Shalaby

mshalaby2004@yahoo.com

1 Department of Geosciences, Universiti Brunei Darussalam, Jalan Tungku Link, Gadong BE1410, Brunei Darussalam

2 Geology Department, Faculty of Science, Tanta University, Tanta 31527, Egypt to Eocene aged sandstone (Higgs et al. 2017; King and Thrasher 1996; Ministry of Business, Innovation and Employment, New Zealand 2014). Both oil and gas condensate have been discovered within the Paleogene reservoirs; however, the Neogene reservoirs primarily accumulated oil (Ministry of Business, Innovation and Employment, New Zealand 2014). In addition, stacked reservoirs are frequently found within the Maui, Kapuni and Rimu/Kauri fields.

The Kaimiro Formation is a subdivision of the Kapuni Group and of Paleocene to Eocene age. This formation is the second lowermost part of the group and consists of older sandstone, mudstone and siltstone sequences. The lithofacies of this formation in the Taranaki Basin are shoreline and lower coastal plain sandstones, similar to the lithofacies present at the uppermost of the Kapuni Group, which are the Mangahewa and McKee Formations (King and Thrasher 1996). According to the Ministry of Business, Innovation and Employment (2014), Kaimiro Formation has a porosity of over $20 \%$, a permeability of submilli-Darcies $(\mathrm{mD})$ to 


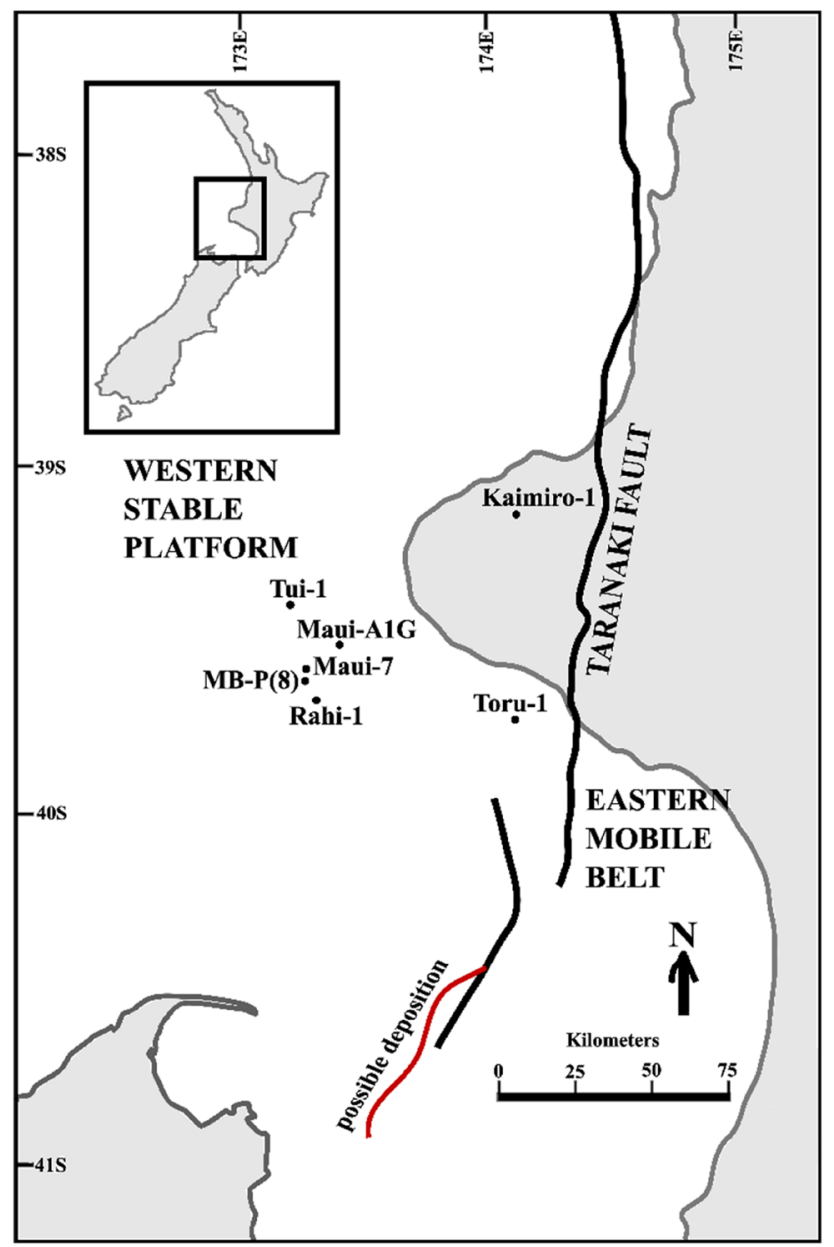

Fig. 1 Location of the Taranaki Basin and the studied wells, modified after Ministry of Business, Innovation and Employment, New Zealand (2014) and Palmer (1985)

several Darcies and has a production rate of 11,000 barrels of oil per day (bopd) to date. This production rate is acquired from the Maui Field, which encompasses of both oil and gas condensate (Ministry of Business, Innovation and Employment, New Zealand 2014).

There have been a few similar analyses conducted on the Kaimiro Formation and other formations within the Kapuni Group with different approaches. On the other hand, Higgs et al. (2017) accomplished a reservoir characterization on the same formation of interest utilizing an interdisciplinary method, which include biostratigraphy, $\log$ facies and stratigraphic correlation of the formation. Additionally, similar integrated reservoir characterization studies in the Taranaki Basin have previously been made such as Jumat et al. (2018), Dong et al. (2018), Qadri et al. (2019a) and in many other fields such as Shalaby et al. (2014a, b, 2016, 2018), Shalaby and Islam (2017), Osli et al. (2018) and Qadri et al. (2019b). According to Cade et al. (1994), the performance and presentation of sandstone reservoir are mainly influenced by various factors, such as the textural and diagenetic properties like grain size, sorting type, compaction, cementation and dissolution. Hence, this study will investigate the parameters and processes to give the reservoir production of the Kaimiro Formation.

The concept of the hydraulic flow unit, RQI, FZI, porosity and permeability determination and relationships has been applied in this research study for more detailed interpretation of the reservoir. These methods have been previously studied in several researches done by Timur (1968), Winland (1972, 1976), Kolodzie (1980), Amaefule et al. (1993), Tiab and Donaldson (2012). Many other research studies have been done to apply and test these models in different reservoirs for example (Nabawy and Al-Azazi 2015; El Sharawy and Nabawy 2019).

The main objectives of this study are to utilize a combination of different datasets to evaluate and understand the reservoir quality evolution of the Kaimiro Formation. The study comprises petrophysical parameters (porosity and permeability) and the interaction between them that affects the reservoir potentiality. Sedimentological and petrographical description can help to evaluate the textural and diagenetic features controlling the reservoir development. Well log interpretation is also another important method which can help to evaluate the reservoir enhancement through some important parameters such as volume of shale, porosity, water and hydrocarbon saturation. Some derivative parameters from porosity and permeability such as Normalized Porosity Index (NPI), reservoir quality index (RQI) and the flow zone indicators (FZI) are used for better understanding of the reservoir quality and the presence of fluid flow units. The determination of pore throat diameters (r35) is also considered for the first time in this formation. Therefore, this kind of combination methods and analyses can be considered as unique and outstanding application and very helpful to evaluate reservoir heterogeneity, fluid flow and potentiality.

\section{Geological background}

\section{General geology}

The Taranaki Basin, which is named after a large Pleistocene volcano situated on the northern island of New Zealand, Mount Taranaki, is a Late Cretaceous-Cenozoic sedimentary basin positioned primarily offshore and relatively onshore in the central western part of North Island of New Zealand (Uruski et al. 2003). According to New Zealand Petroleum and Minerals (2014), major tectonic activities in the Cretaceous led to the development of the Great South Basin. New Zealand was completely disjointed from the east of the supercontinent Gondwana in the Late 
Cretaceous, which resulted in the separation between Australia and Zealandia. This eventually led to the formation of the Tasman Sea, in which this occurrence was signified by widespread marine transgression that took place in Oligocene. Numerous extensional basins of the New Zealand subcontinent included the formation of an intra-plate rift called the Taranaki Rift and ultimately developed into the Taranaki Basin during the Late Cretaceous (Thrasher 1992; Laird and Bradshaw 2004; Kroeger et al. 2013; Baur et al. 2014).

The Taranaki Basin is composed of two major structural blocks: the Eastern Mobile Belt, also known as the Taranaki Graben, and the Western Stable Platform (Fig. 1) (Pilaar and Wakefield 1978; Knox 1982). The Western Stable Platform, which is over $150 \mathrm{~km}$, completely covers the offshore western part of the basin and is described to be a broad and simple structure consisting of 2000-5000 m of Late Cretaceous to Recent sediments (Palmer 1985). This structural block has remained stable throughout the remainder of the Tertiary, even though it was affected by the normal block faulting that occurred in the Late Cretaceous to Eocene (Jumat et al. 2018). The sedimentary sequence was not affected and left undisturbed since the Late Eocene (Knox 1982).

On the other hand, the Eastern Mobile Belt, which extends over $80 \mathrm{~km}$ of faulted depression situated on the eastern side of the basin, contains several tectonic processes and evolution. Additionally, it has a complex structure and consists of sediments up to $11,000 \mathrm{~m}$ (King and Thrasher 1996).

The general stratigraphy of the Taranaki Basin consists of several groups, with each group comprising of several petroleum-bearing formations of different ages (Fig. 2). The groups from the Late Cretaceous to the Pleistocene include the Pakawau Group, Kapuni Group, Moa Group, Ngatoro Group, Wai-titi Group and Rotokare Group, arranged from the oldest to the youngest. (King and Thrasher 1996; Ministry of Business, Innovation and Employment, New Zealand 2014).

\section{The Kapuni Group and the Kaimiro Formation}

Within the basin, most of the hydrocarbon reserves have been collected and discovered in the northeast to southwest trending sandstones of the Paleogene strata and this strata is segmented into two groups: the fully marine Moa group and the continental to shallow marine Kapuni Group (King and Thrasher 1996).

The formation of interest for this study, the Kaimiro Formation, is a subdivision of the Kapuni Group. The Kapuni Group consists of a measure sequence of sandstone, mudstone and coal of Paleocene to Early Oligocene age (Palmer 1985). This group is sectioned into four formations according to their age and lithology (Fig. 2). The lower parts of the group consist of the Paleocene to Earliest Eocene Farewell

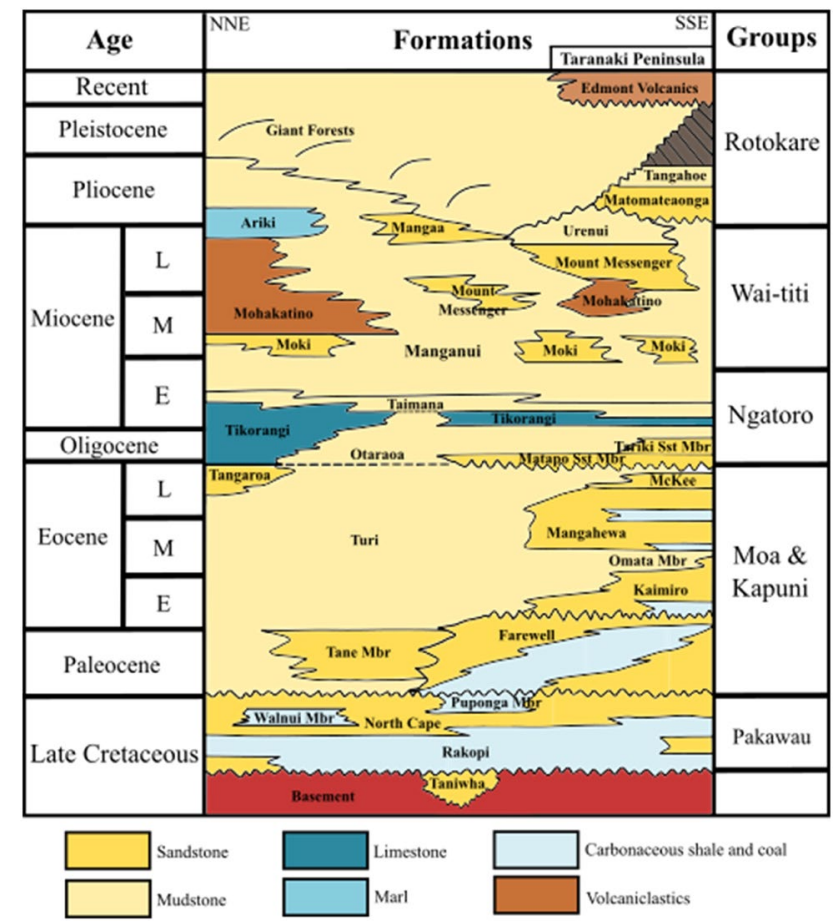

Fig. 2 The generalized stratigraphy of the Taranaki Basin, modified after Jumat et al. (2018)

Formation and the Early to Middle Eocene Kaimiro Formation, whereas the upper part of the Kapuni Group comprises the Middle to Late Eocene Mangahewa Formation and the Uppermost Eocene McKee Formation (King and Thrasher 1996; Palmer 1985).

The upper part of the Kapuni Group is signified by a major sedimentation change where the lithology changes from a sandstone to a massive silty mudstone to an underlying unit of coal measure sequence (Palmer 1985). However, the distribution and lateral changes within the lower part of the Kapuni Group are not as well recognized as the allocations as those at the upper part of the group, due to the lower part of the Kapuni Group comprising a sequence of marine siltstone and mudstone to an older sandstone to mudstone sequence (Palmer 1985). Eventually, this then created the Kaimiro Formation. Kaimiro Formation, termed after the North Taranaki township of Kaimiro, is one of the lower formations of the Kapuni Group, and it comprises primarily sandstone with interbedded mudstone and siltstone (Palmer 1985). It has an age of Early to Middle Eocene (45-55 Ma) and is distributed across the Taranaki shelf and onshore of Taranaki Basin (Ministry of Business, Innovation and Employment, New Zealand 2014). Kaimiro Formation, alongside the Farewell and Mangahewa Formations, contains a consistent extent of laterally equivalent facies deposited across a broadly defined synchronous, shoreline belt trending at northeast to southwest and coastal plain 
(Ministry of Business, Innovation and Employment, New Zealand 2014).

\section{Data and methodology}

Data from five wells Toru-1, Tui-1, Maui-A1G, Maui-7 and MB-P (8) within the basin have been chosen for this study. Petrophysical datasets from core analyses, photomicrographs and well $\log$ data were acquired from the Ministry of Business, Innovation and Employment of New Zealand (2014). The integrated study using all available methods and techniques aids in verifying an overall overview and evaluating the Kaimiro Formation as a potential reservoir. The methods applied in this study consist of a variety of interpreted methods and techniques. Full interpretation of the petrophysical parameters porosity and permeability and their derivatives NPI, RQI and FZI have been applied on the Kaimiro Formation. Sedimentological and petrographic description of some selected thin section from the studied wells is also used for further explanation of the factors affecting the reservoir quality. Moreover, well log interpretation using interactive petrophysics has been applied on selected dataset of the Kaimiro Formation in two different wells.

\section{Petrophysical analysis}

This method has been carried out to examine the reservoir quality based on the two important petrophysical parameters of the selected samples. Five wells within the basin have been chosen for this approach: Maui-7, Maui-A1G, MB-P(8), Toru-1 and Tui-1. A porosity-permeability relationship graphs and some other histograms have been produced to study the correlation between the two parameters on the selected samples. Additionally, some important parameters have been calculated based on the porosity and permeability for more discover the reservoir quality evolution in the Kaimiro Formation. Reservoir Quality Index (RQI), Normalized Porosity Index (NPI) and Flow Zone Indicator (FZI) have been counted to explain the fluid flow properties within the Kaimiro sandstone.

The percentage of pore volume to matrix volume parameter is known as the Normalized Porosity Index (NPI) and can be obtained simply by this formula:

$\mathrm{NPI}=\Phi /(1-\Phi)$

The porosity and permeability have been related to each other in the form of the reservoir quality index (RQI):

$\mathrm{RQI}=0.0314 \sqrt{\frac{K}{\Phi}}$ where permeability, $k$, is measured in $\mathrm{mD}$ and $\Phi$ is porosity in percentage $(\%)$.

The Flow Zone Indicator (FZI) is found as:

$\mathrm{FZI}=\mathrm{RQI} / \mathrm{NPI}$

The pore throat radius (r35) proposed by Winland (1972, 1976) accounts for the interrelationship of porosity and permeability making them effective methods for comparing rock quality (Kolodzie 1980)

$\log \mathrm{r} 35=0.732+0.588 \log K_{\mathrm{air}}-0.864 \log \Phi$ core

where $\mathrm{r} 35$ is the pore throat radius at $35 \%$ mercury saturation, $K$ is air permeability $(\mathrm{mD}), \Phi$ is porosity $(\%)$.

\section{Sedimentological and petrographical descriptions}

Photomicrographs of thin sections from wells Maui-7, MauiA1G, MB-P(8), Toru-1 and Tui-1 at specific depths were utilized for better understanding of the important features that may or may not affect the Kaimiro reservoir. Diagenetic features such as compaction, cementation, dissolution and the presence of clay minerals are examined, which aid to determine the impact of these features to the reservoir properties and the reservoir quality of the formation.

\section{Well log analysis}

Log-based petrophysical analysis from wells Maui-7, MB-P(8) has been accomplished by Neuralog and Interactive Petrophysics (IP) software. Neuralog was utilized to convert the printed log format into LAS format prior to loading into Interactive Petrophysics. Subsequently, IP was then utilized for complete well log interpretation of the uploaded data. It is mostly can help to determine the lithology types, fluid types, porosity and the hydrocarbon potential of the Kaimiro Formation. The conventional well log dataset available for this analysis includes Gamma Ray (GR), Caliper (CALI), Neutron (NPHI), Density (RHOB), Sonic (DT), Deep Laterolog Resistivity (LLD), Shallow Laterolog Resistivity (LLS) and Microspherical Focused Log (MSFL). Two interpretations methods have been completed for this study: qualitative and quantitative analysis. Several cut-off values have been applied such as shale volume cut-off, porosity cutoff and water saturation cut-off in order to find the promising net pay zones at every well and their certain specific depths. 


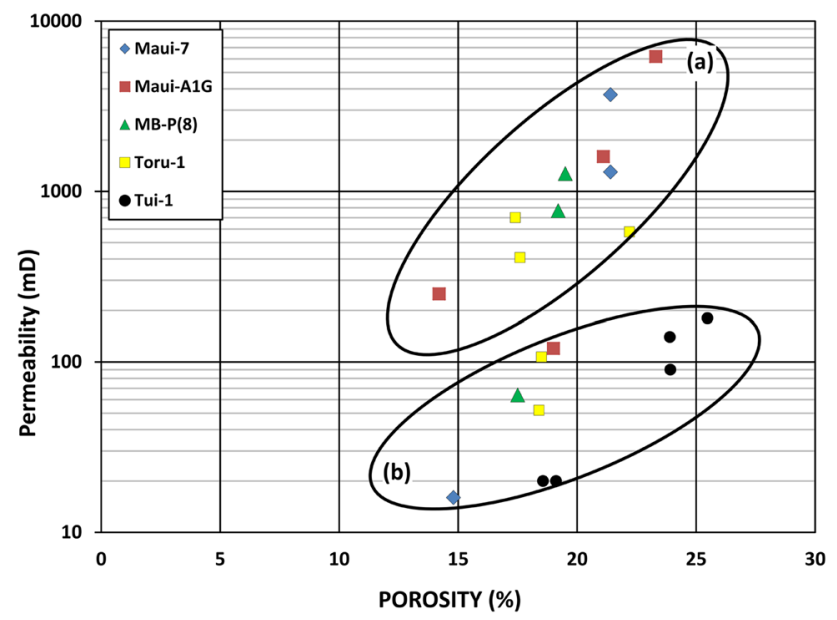

Fig. 3 A cross-plot of porosity-permeability relationship for the Kaimiro Formation in the studied wells

\section{Results and discussion}

\section{Porosity permeability relationships}

Petrophysical analysis of the Kaimiro Formation has been achieved to study the relationship between the two important petrophysical parameters: porosity and permeability. Based on the majority of the porosity and permeability percentages within the studied wells (Fig. 3), the values are classified to have a fairly good to very good porosity (Levorsen 1967; Tiab and Donaldson 2012) and a good to very good permeability (Levorsen 1967). The overall porosity ranges from 14.2 to $25.48 \%$, with a mean of $19.8 \%$, while the permeability values range between 16 and $6200 \mathrm{mD}$, with a mean of $879.45 \mathrm{mD}$. Figure 3 shows the porosity-permeability cross-plot that shows a good positive correlation, in which the permeability increases with increasing porosity.

Two trend lines are deduced, in which both lines show a positive correlation (Fig. 3). In the first trend zone (a), most of the plotted data points are involved in the plot excluding data from Tui- 1 well and some other scattering. It shows that the permeability increases immensely with porosity, in which the permeability values reach up to $6200 \mathrm{mD}$ which can be interpreted as samples representing clean sandstones (Fig. 3). It also most probably indicates that samples are affected by good porosity with more and wide routes for migration and fluid flow.

In the other trend zone (b), data from Tui-1 well and some other scattering from other wells are involved. It demonstrates that the permeability values between 10 and $110 \mathrm{mD}$ still have high porosity values reaching more than $25 \%$. The samples in zone (b) are interpreted as clay-cemented sandstones which may be affected by some cemented materials
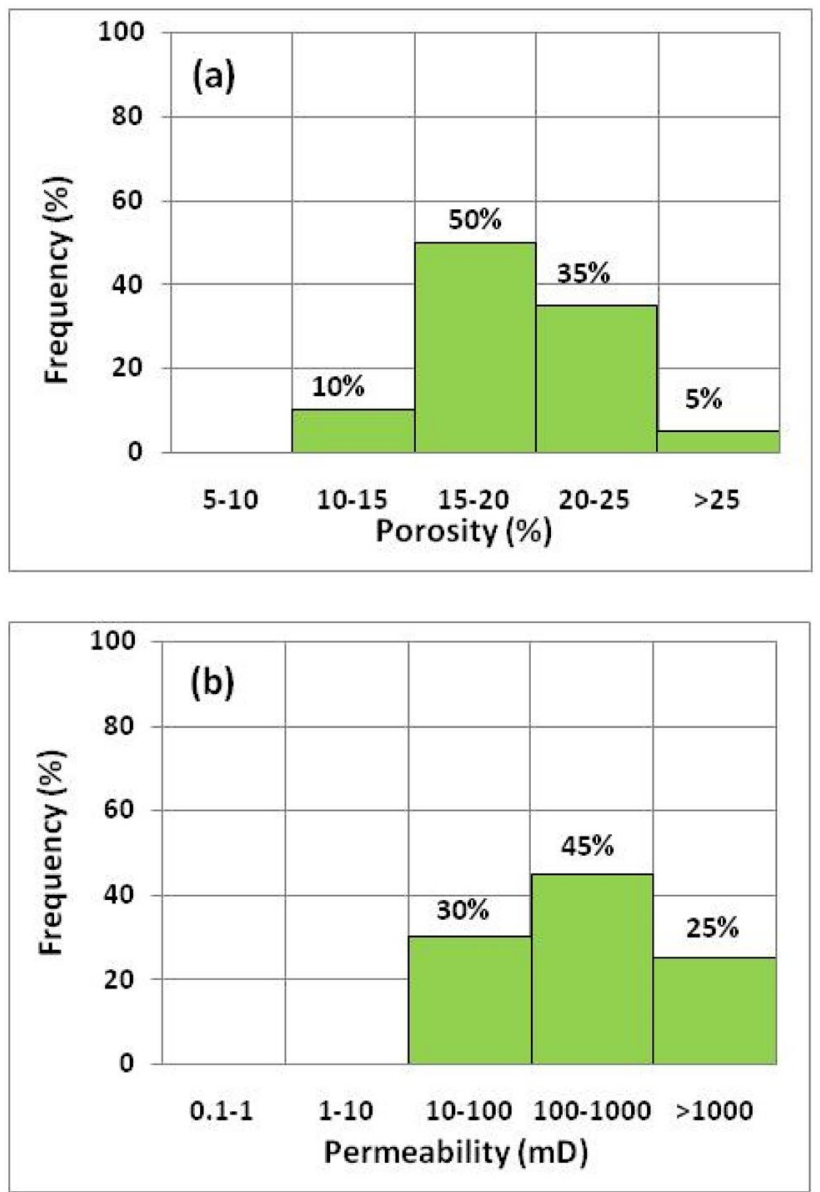

Fig. 4 Porosity and permeability histograms to show the petrophysical variation in the Kaimiro Formation

most probably of clay type which may reduce the permeable zones (Fig. 3).

Figure 4 shows the porosity and permeability histograms for the Kaimiro Formation. It is observed that porosity histogram (Fig. 4a) shows wide range of porosity (>10-25). 50\% of the samples have porosity more than $15 \%(\Phi=15-20)$, $35 \%$ ( $\Phi=20-25 \%)$, while only $5 \%$ of the samples contain porosity higher than $25 \%$ (Fig. 4 a). This indicates that most of the samples from the Kaimiro Formation indicating good reservoir quality. Figure $4 \mathrm{~b}$ shows the permeability histogram indicating god permeability ranging from 16 to $6200 \mathrm{mD}$. It shows that $30 \%$ of the samples have permeability from 10 to $100 \mathrm{mD}$, while $45 \%$ of the samples have permeability from 100 and up to $1000 \mathrm{mD}$ (Fig. 4b). It is also observed that $25 \%$ contains permeability higher than 1000 and reaches $6200 \mathrm{mD}$.

The relationships of porosity and permeability versus depth are illustrated in Fig. 5. Samples from Maui-7, MauiA1G, MB-P (8) and Tui-1 wells are found to be within similar depth interval, while data from Toru-1 well are more deeper. Excluding Toru-1 samples (which is far deeper), all

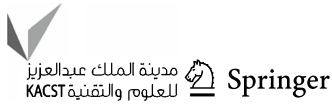


Fig. 5 Porosity and permeability graphs versus depths for the selected Kaimiro Formation in the studied wells

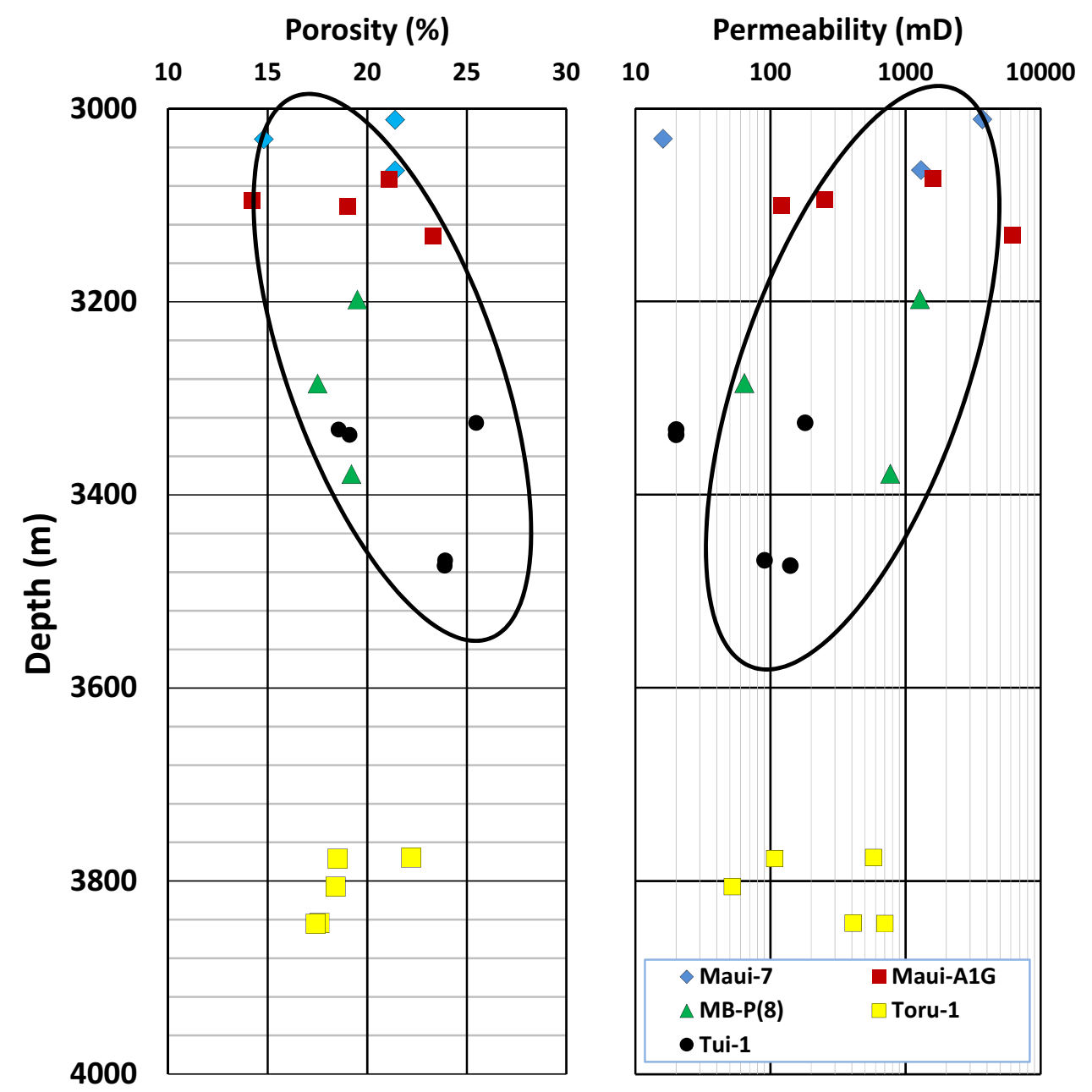

other data show homogenous relationship with depth. Figure 5 displays the increase in porosity with depth (positive correlation) while permeability decreases (negative correlation) (Fig. 5). The decrease in permeability with depth in contradiction of porosity can be attributed to the presence of some cementing and authigenic clayey materials which may affect the permeability not the porosity (Shalaby et al. 2014a, b, 2016; Jumat et al. 2018; Dong et al. 2018; Osli et al. 2018). Therefore, the petrographic description is important to explain and validate the reasons behind the features.

\section{Sedimentological and petrographical studies}

Sedimentological and petrographical descriptions have been accomplished for the Kaimiro Formation as distinct features and rock textures are observed. This approach is essential as diagenetic events aid to determine how much the network had changed the original pore throughout and following the burial of the sediments (Jumat et al. 2018). The primary or intergranular pores are visible in all of the samples and are expected largely made up of macropores or megapores.
Diagenesis, such as the cementation of carbonate, silica and iron oxide, and the presence of clay minerals such as kaolinite, occupied some of the pores, thus affecting the permeability. Secondary pores (SP) produced by diagenetic events of compaction and dissolution (Schmidt et al. 1979; Ehrenberg 1990) are also dominant, thus enhancing the porosity and the reservoir quality of the Kaimiro Formation. However, the effect of diagenetic features will be minimized in case of coarse grain sandstone, while the petrophysical parameters remain as a good quality.

\section{Diagenetic control}

Compaction is one of the main diagenetic processes that occurred in the studied samples of the Kaimiro sandstone. Compaction is recognized in the studied samples by the existence of crushed grains (Fig. 6a-d) and the presence of contacts such as long contacts (Fig. 6c) and concavo-convex contacts (Figs. 6d-f, 7a, e) and fractures (Fig. 6d-f). The crushed quartz and feldspar and the presence of fractures produce secondary pores, thus enhancing the porosity of 

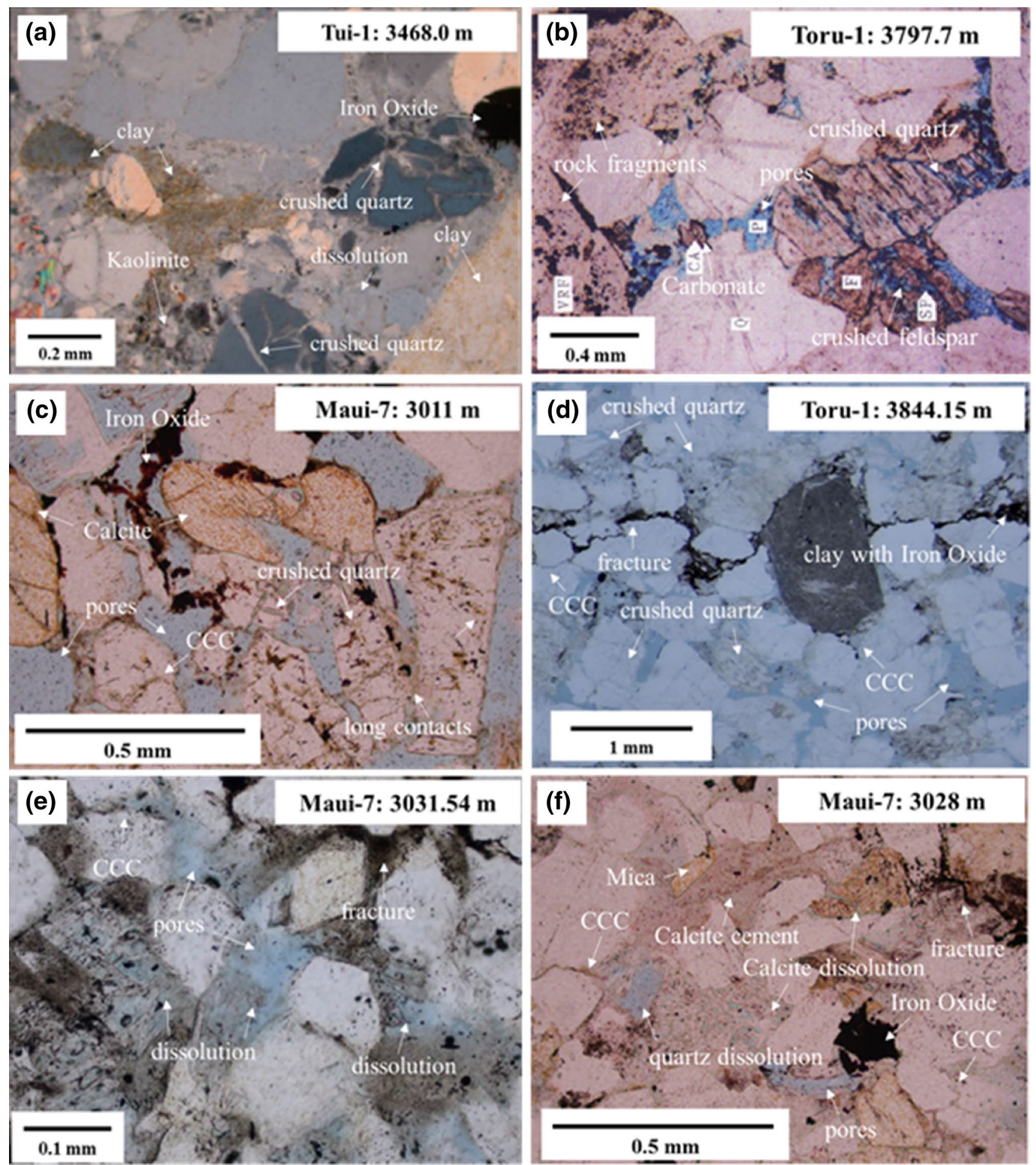

Fig. 6 Thin section photomicrographs of medium- to fine-grained Kaimiro sandstone. The main features observed in a-e are the primary intergranular pores (stained blue) and secondary pores (SP) caused by diagenetic features. Other features observed in the selected sample data: a crushed quartz, quartz dissolution, the presence of kaolinite and pore filling clay; b crushed quartz and feldspar, the presence of rock fragments and carbonate; c crushed quartz, long

contacts (LC), concavo-convex contacts (CCC), iron oxide cement and calcite; $\mathbf{d}$ crushed quartz, concavo-convex contacts (CCC) and a large fracture containing clay and iron oxide; e dissolution of quartz and feldspar, a fracture and concavo-convex contacts (CCC); f concavo-convex contacts (CCC), a fracture, secondary minerals such as calcite and mica, dissolution of calcite and cementation of calcite and iron oxide 

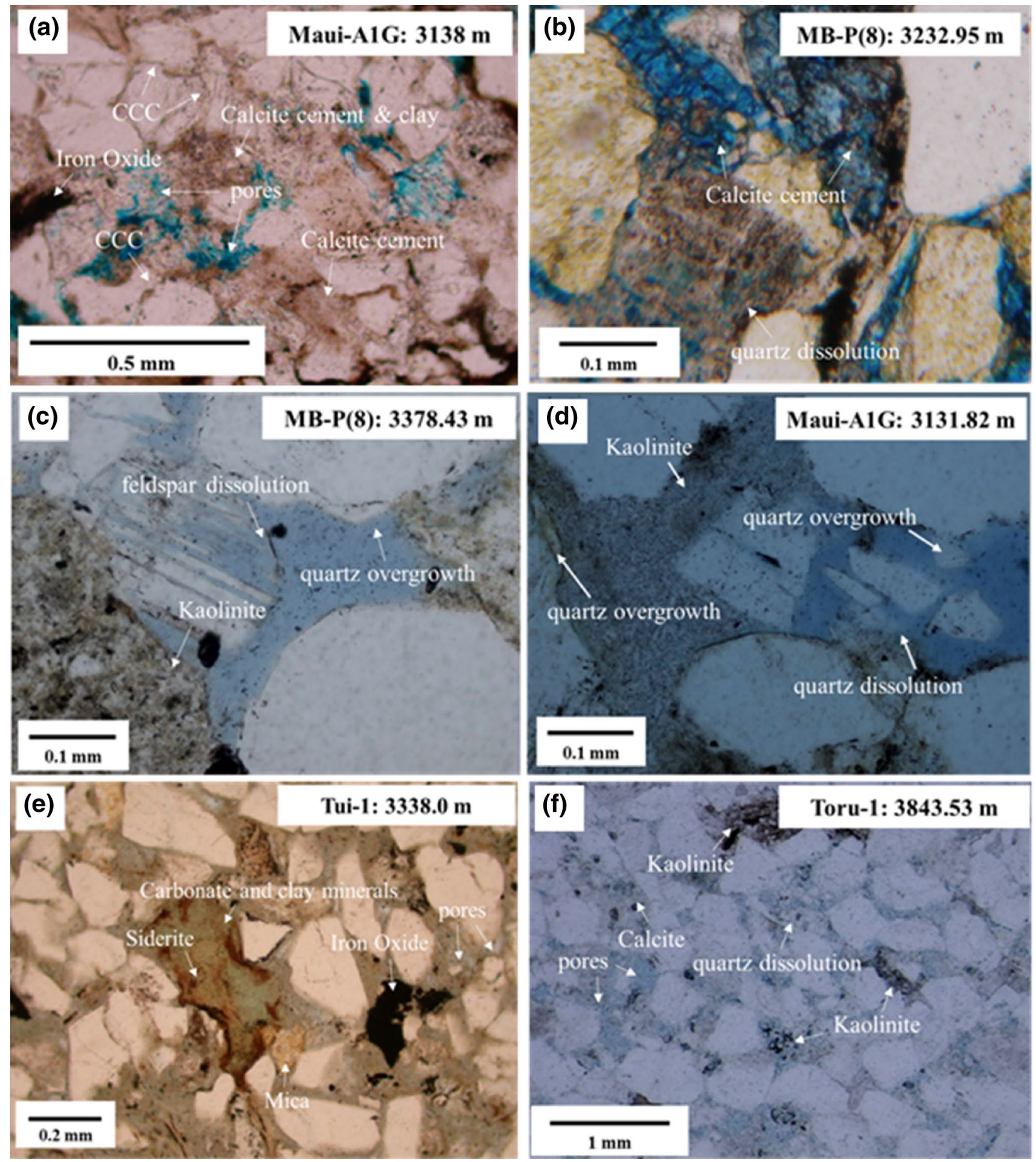

Fig. 7 Thin section photomicrographs of medium- to fine-grained Kaimiro sandstone. Other features are observed in the selected sample data: a concavo-convex contacts (CCC), clay and calcite cement, along with iron oxide filling pores; $\mathbf{b}$ quartz dissolution and carbonate cement (stained bright blue); c feldspar dissolution, quartz over-

growth and the presence of kaolinite; d quartz dissolution, quartz overgrowth and the presence of kaolinite; e carbonate with clay minerals, iron oxide and mineral replacement of siderite and mica; (f) quartz dissolution, mineral replacement of calcite and the kaolinite filling pores 
the samples. Compaction was mostly detected especially in deep basins, and compaction with various contacts reduces the petrophysical parameters (Fig. 6a-d). This corresponds to the study by Higgs et al. (2017) as they also mentioned that compaction has reduced intergranular pore volume in all the samples of the Kaimiro Formation, affecting mostly the deeply buried wells. Additionally, the presence of several long and concavo-convex indicated that the formation of interest may have undergone through a moderate or high degree of compaction (Al Areeq et al. 2014; Shalaby et al. 2014a, b, 2016). However, secondary pores were also produced as a result of intense compaction; thus, this feature also led to the increase in the petrophysical parameters of the samples as well. As the grains are subjected to deep burial depths and high pressure, the crushing of grains may be extensive, producing secondary pores and enhancing the porosity (Fig. 6a-d). Furthermore, microfractures may sometimes be produced by intense compaction of the grains (Fig. 6d-f), which increases the porosity as fluids such as hydrocarbons may occupy the fissure (Worden and Morad 2000). However, the fractures within the sample may be inhabited by other minerals such as iron oxide and clay (Fig. 6d), which reduces the porosity instead.

Cementation is another major diagenetic feature in the studied samples of the Kaimiro sandstone and has a damaging effect on the reservoir quality as this process reduces the porosity and permeability of the samples. The types of cements that are established are carbonate, silica, iron oxide and clay minerals. Carbonate or calcite cementation is observed occupying the pore spaces (Figs. 6f, 7a, b). Silica cement was formed early in the initial diagenetic stage and in a shallow marine diagenetic setting (Baiyegunhi et al. 2017). The dissolution of feldspar grains frequently produces the precipitation of quartz around the existing detrital grains. This is commonly known as quartz overgrowth (Worden and Morad 2000; Rossi et al. 2001), and they appear as syntaxial overgrowth within the samples (Fig. 6c, d). Other cement minerals such as iron oxide (Figs. 6a, 7a, c, f) and clay (Fig. 7e) are observed to occur occasionally within the studied samples of the Kaimiro sandstone (Rossi et al. 2001; Worden and Morad 2003; Shalaby et al. 2014a). Both clay minerals and iron oxide occupy pore and fracture spaces which further decrease the storage capacity and migration pathways for fluids. The presence of clay minerals in the Kaimiro sandstone occurs commonly as kaolinite crystals and were observed between the grains (Figs. 6a, 7c, f). Occasionally, kaolinite is observed to be surrounded by quartz overgrowth (Fig. 7c, d). (Worden and Morad 2003; Rossi et al. 2001; Jumat et al. 2018).

Dissolution is an extremely important diagenetic feature for the reservoir rock characterization and leads to the augmentation of porosity and permeability (Shalaby et al. 2014a, b, 2016). The dissolution of the minerals that occur within the samples were quartz dissolution (Figs. 6a, e, 7b, $\mathrm{d}, \mathrm{f})$ and dissolution of unstable minerals such as feldspar (Fig. 7c) and calcite (Fig. 6f). Secondary pores by dissolution commonly produce two types of dissolution porosity: isolated voids (Fig. 6a-f) and voids that are well connected to the intergranular pore network (Figs. 6,7). The wellconnected voids are mostly evident, where the dissolution of quartz enhanced the primary porosity, and the latter is referred to as hybrid porosity (Figs. 6b, e, f, 7c, d, f). Hybrid porosity is the co-occurrence of the primary pores and secondary pores, and this increases the permeability and thus the reservoir quality of the sandstone.

On the other hand, dissolution is observed to enhance the permeability of the Kaimiro sandstone. The dissolution of quartz may be triggered by the presence of clay minerals (Fig. 7d, f) as dissolution may be augmented by the dehydration of clay minerals (Jinliang et al. 2007). Moreover, the dissolution of feldspars may precede to the discharge of silica, hence establishing quartz cement including quartz overgrowth (Fig. 6c) (Baiyegunhi et al. 2017). Permeability is also enhanced by dissolution as this feature occasionally generates hybrid porosity (Figs. 6b, e, f, 7c, d, f).

\section{Impact of diagenesis on the reservoir quality}

The impacts of the different diagenetic properties are clearly observed affecting the reservoir quality of the Kaimiro Formation in the study area. The dissolution of quartz, feldspare and other clay minerals acts for enhancing the reservoir quality, while, on the other hand, different types of cements are strongly destroying it. Therefore, the interaction and relationships of the different diagenetic features versus the petrophysical parameters (porosity and permeability) should be considered in more detail. The impacts of total cement, quartz overgrowth and authigenic clay on the petrophysical parameters are shown in Fig. 8. The presence of total cement (Fig. 8a, b), quartz overgrowth (Fig. 8c, d) and authigenic clay (Fig. 8e, f strongly decreases the petrophysical parameters (porosity and permeability), thus destroying the reservoir quality of the formation. It is observed that the plotted data points from all wells (Fig. 8), all displaying negative relationships between the diagenetic features and the petrophysical parameters.

\section{Reservoir zonation and flow units}

Important petrophysical parameters (Normalized Porosity Index (NPI), Reservoir Quality Index (RQI), Flow Zone Indicator (FZI) and the winland pore throat diameter r35) have been calculated to evaluate the sandstone reservoir of the Kaimiro Formation. Figure 9 shows the relationship between RQI and NPI which reveals different flow zone units. The plot shows that samples are characterized by

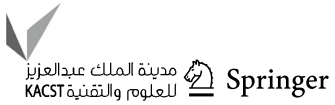



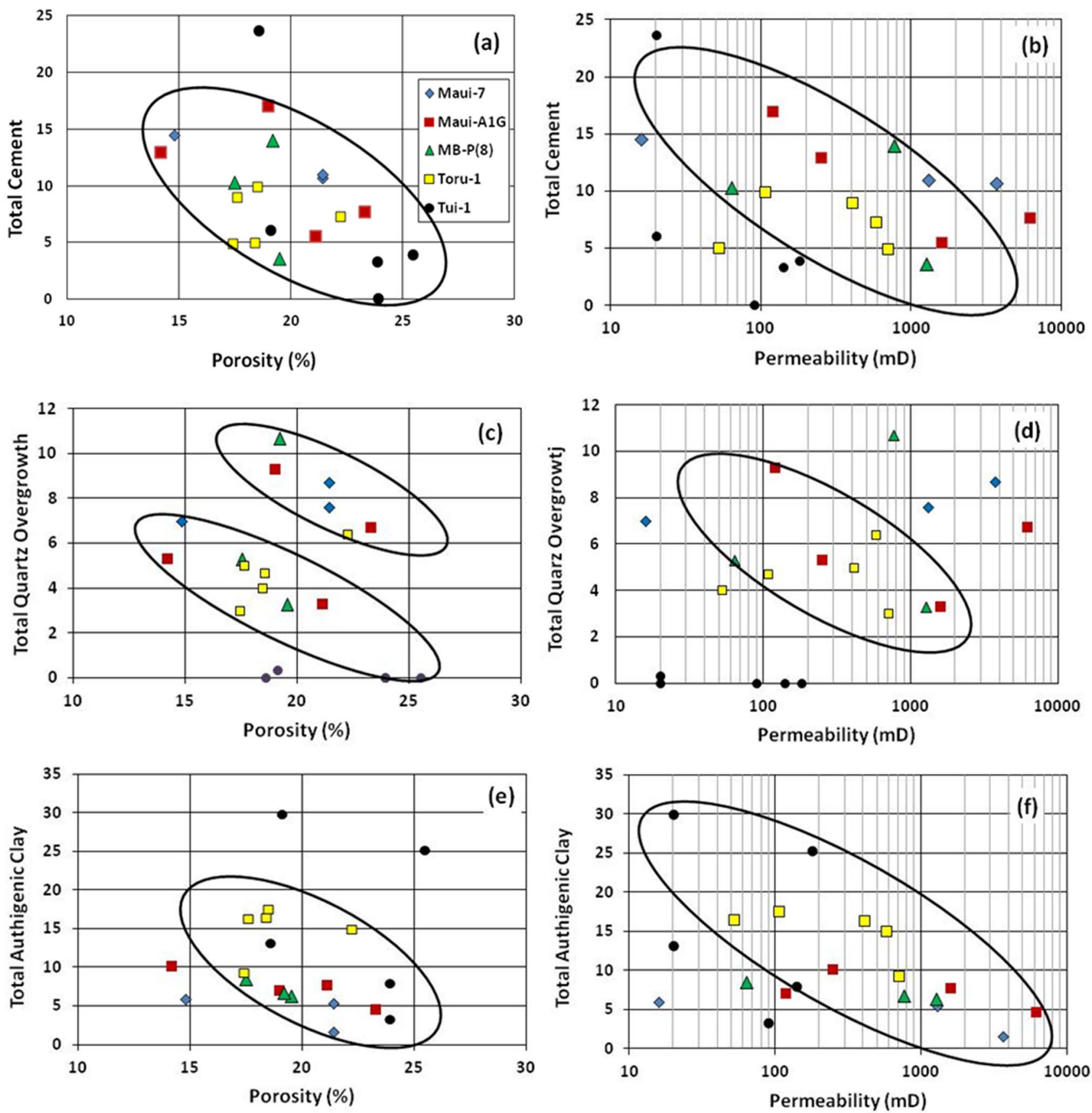

Fig. 8 Porosity and permeability graphs in relation to total cement, total quartz overgrowth and total authigenic clay for the selected Kaimiro Formation wells

wide range of flow units reaching up to $15 \mu \mathrm{m}$. Based on the fluid flow units that are available (Fig. 9), most of the plotted samples having FZI higher than $5 \mu \mathrm{m}$ are interpreted as good reservoir quality (Nabawy and Al-Azazi 2015). Samples with FZI in the range of $2.5-5 \mu \mathrm{m}$ are interpreted as fair reservoir quality. Samples with lower flow units less than $2.5 \mu \mathrm{m}$ are found mostly for data from Tui-1 well which indicate poor reservoir quality (Fig. 9). The relationship of RQI and FZI (Fig. 10) indicates that good-to-excellent reservoir properties (RQI higher than $1 \mu \mathrm{m}$ and FZI more than $5 \mu \mathrm{m}$ ) are expected from most of the samples from Kaimiro Formation based on the classification by Nabawy and Al-Azazi (2015). Some scattered data point mostly from Tui-1 Well, and some other samples can indicate poor-to-fair reservoir quality in good agreement with the interpretation in Fig. 9. The cross-plots of the Winland pore throat radius (r35) 


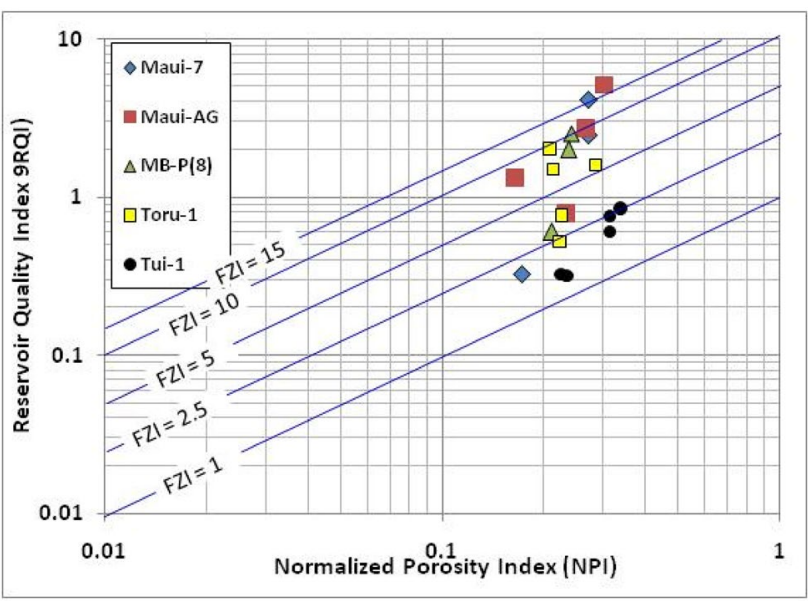

Fig. 9 Plotting of RQI versus Normalized Porosity Index showing hydraulic flow units

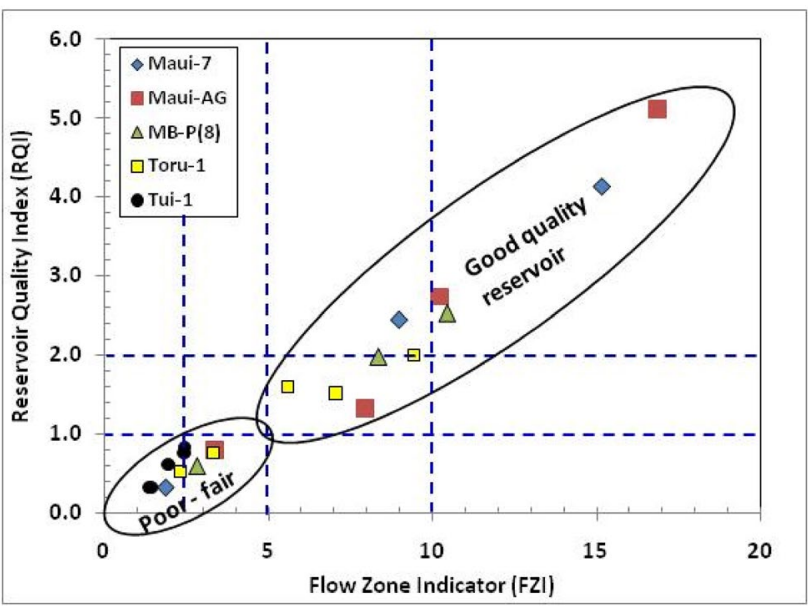

Fig. 10 Plotting of RQI versus Flow Zone Indicator (FZI)

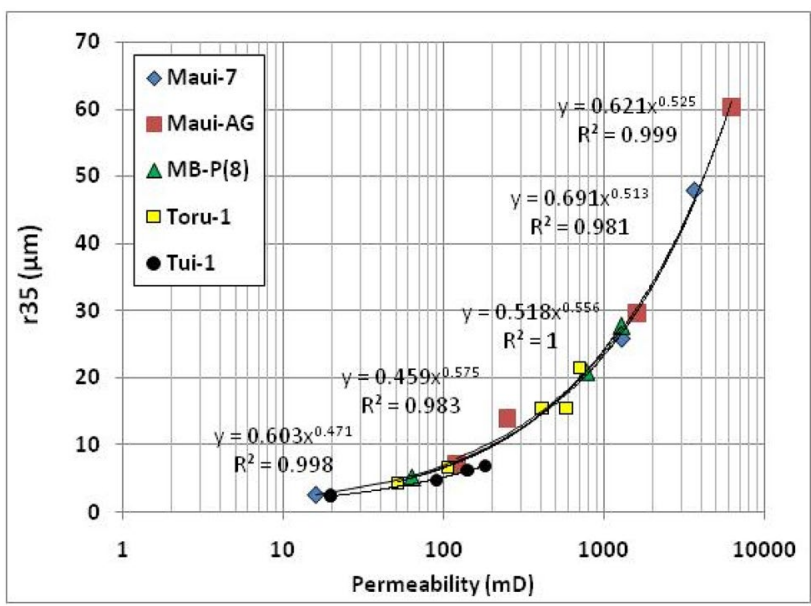

Fig. 11 Plotting of pore throat radii (r35) versus a horizontal permeability $\left(K_{\mathrm{H}}\right)$

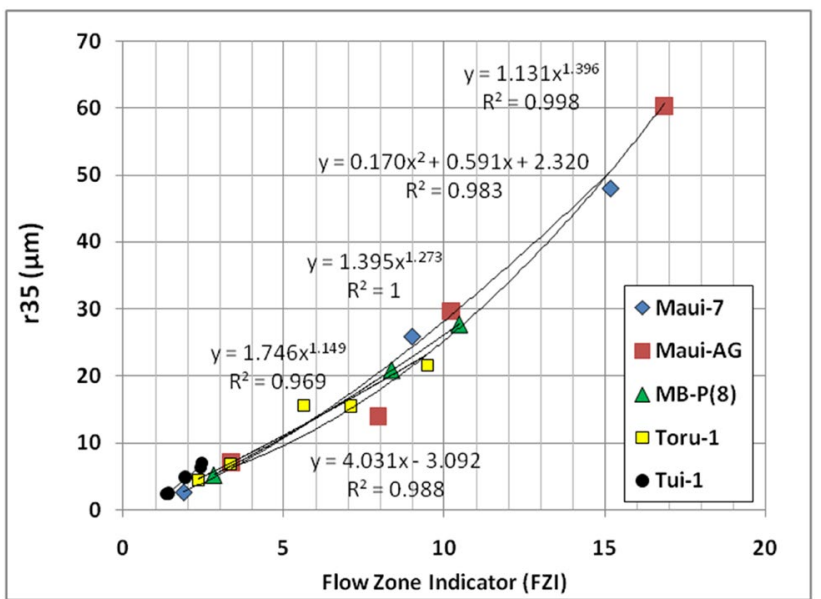

Fig. 12 Plotting of pore throat radii (r35) versus Flow Zone Indicator (FZI)

versus permeability and flow zone indicator (El Sharawy and Nabawy 2019) are presented in Figs. 11 and 12, respectively. Very good positive correlation is observed between r35 and the two parameters. Moreover, R35 parameter can be calculated from both permeability and FZI with very high accuracy and confidence $\left(R^{2}=0.969-1.0\right)$. This indicates that permeability and FZI can be used with a higher degree of confidence to calculate the pore throat diameter r35 in the case of the absence of pressure data. r35 values higher than $10 \mu \mathrm{m}$ are obtained for samples from all wells except Tui-1 well which show poor-to-fair reservoir quality. Figure 13 shows the histogram to show the pore throat diameter and pore-type identification in the studied wells. It has been noticed that the data collected from all wells except Tui-1 show macro- and megapores with almost similar range (Fig. 13). Megapores constitute higher percentages (60\% and above), while macropores have less percentages $(40 \%$ or below). $100 \%$ of the data from Tui-1 well show macropores in good agreement with the cross-plots in Figs. 11 and 12. Hence, higher reservoir quality was observed clearly in all wells while slightly less in Tui-1 well.

\section{Reservoir quality using well log interpretation}

\section{Qualitative interpretation}

From the studied wells, only two wells with promising results were chosen, while thirteen producible sand zones were distinguished, however (Figs. 14, 15). The two wells consist primarily of sandstone, which is exhibited by the low gamma ray values and a negative separation in the neutron-density overlay. On the resistivity track, the wide separation between the three resistivity logs displays the presence of hydrocarbon, which can be further verified

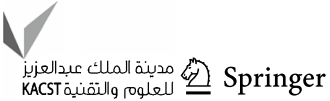



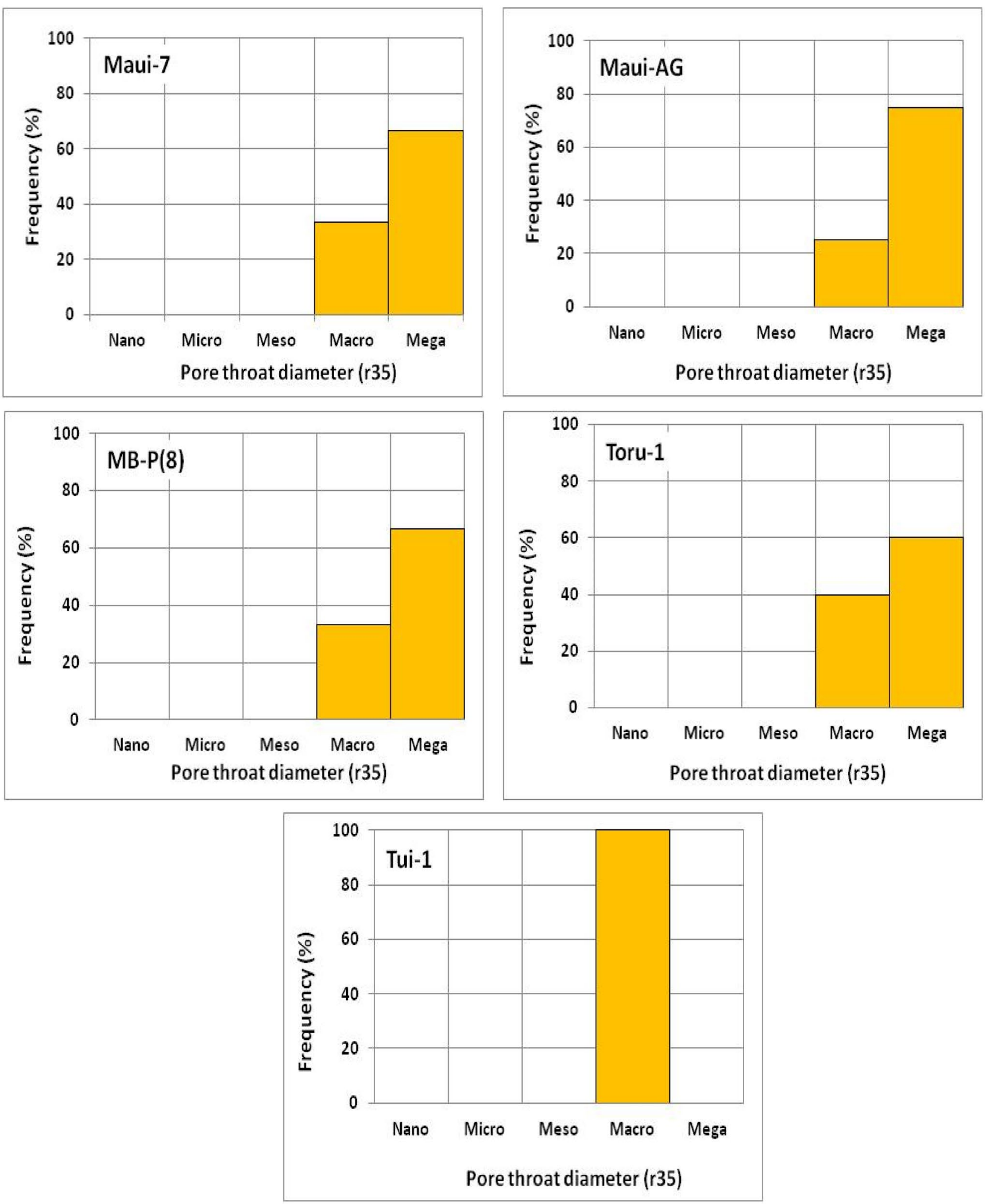

Fig. 13 Pore throat diameter and pore-type identification in the studied wells from r35 parameter 
Fig. 14 Well log interpretation of Maui-7, showing two pay zones with good resistivity separation
Fig. 15 Well $\log$ interpretation of MB-P(8), displaying three potential hydrocarbon-bearing zones with Zone 1 as the most promising zone
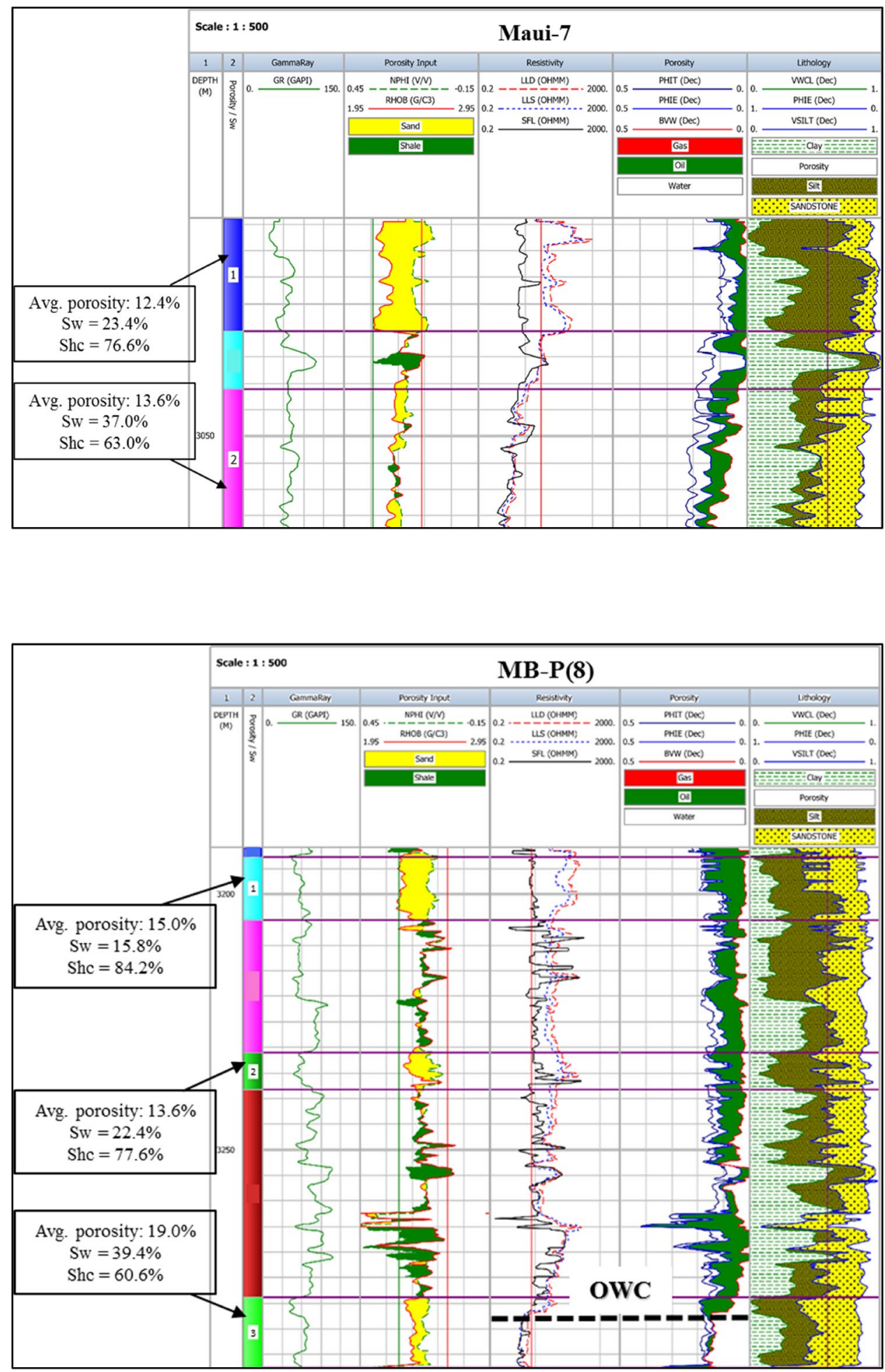

by the quantitative interpretation. Additionally, a high separation of the three resistivity logs signifies the permeability of the formation (Shalaby et al. 2016, 2018). On the other hand, the narrow separation between the three resistivity logs indicates the presence of water-bearing zone. Oil-water contact (OWC) can be expected also in well MB-P(8) at depth approximately $3283 \mathrm{~m}$, where all three resistivity logs start to intersect (Fig. 15). Overall, 
the outcomes of the interpreted porosity track of both wells displayed low water saturation, high hydrocarbon saturation and good effective porosity.

\section{Quantitative Interpretation}

A quantitative analysis of the well log data consists of interpreted petrophysical results obtained by IP. These values were calculated and averaged subsequent to applying cutoffs; thus, these aid to verify the results that were attained from the quick-look approach. The acquired petrophysical parameters include the net reservoir, net pay, average effective porosity, average clay volume, average water saturation and average hydrocarbon saturation (Table 1).

According to Table 1, the average effective porosity of the studied wells comprises values ranging from 14.6 to $16.3 \%$, which signifies fairly good-to-good porosity values (Levorsen 1967; Schlumberger 1989; Tiab and Donaldson 2012). The average clay volume of the studied wells was also found to be low (Table 1). These represent that the wells comprise mainly sandstone and silt, as observed in the lithology track (Figs. 14, 15).

Well Maui-7 consist of two pay zones: Zone 1 from 3009 to $3030.18 \mathrm{~m}$ (21.18 m thick) and Zone 2 from 3041.16 to $3067.37 \mathrm{~m}$ (26.21 m thick) (Fig. 14). In terms of the resistivity readings, Zone 1 is the most promising zone which has a large separation, with a low water saturation of $23.4 \%$. Conversely, it is observed that the resistivity logs within Zone 2 overlap each other, indicating water-bearing zone. In general, well Maui-7 has a good average effective porosity of $16.3 \%$ and a low average water saturation of $27.7 \%$. Hence, this well has a good average hydrocarbon saturation of $72.3 \%$ with a net pay of $36.35 \mathrm{~m}$.

Alternatively, well MB-P(8) has three pay zones: Zone 1 from 3192.83 to $3205.02 \mathrm{~m}$ (12.19 m thick), Zone 2 from 3231.08 to $3238.24 \mathrm{~m}$ (7.16 m thick) and Zone 3 from 3278.78 to $3292.5 \mathrm{~m}$ (13.72 m thick) (Fig. 15). The most promising zone in this well is Zone 1 as it has the lowest water saturation value (15.8\%), the highest hydrocarbon saturation value (84.2\%) and a good effective porosity (15.0\%). The oil-water contact was also established within Zone 3 at around $3282.7 \mathrm{~m}$, in which the water saturation value $(39.4 \%)$ is the highest among the three zones in this well. Overall, the good average effective porosity and low water saturation values for well MB-P(8) are $14.6 \%$ and $24.2 \%$, respectively. Therefore, this well has a very good hydrocarbon saturation of $75.8 \%$ and a net pay of $93.65 \mathrm{~m}$.

Based on the well log results, the studied wells exhibit good reservoir characteristics, with well MB-P(8) as the most productive well based on the net pay, average effective porosity and average hydrocarbon saturation values (Table 1). As a result, the positive relationship between the qualitative and quantitative interpretation performed in IP
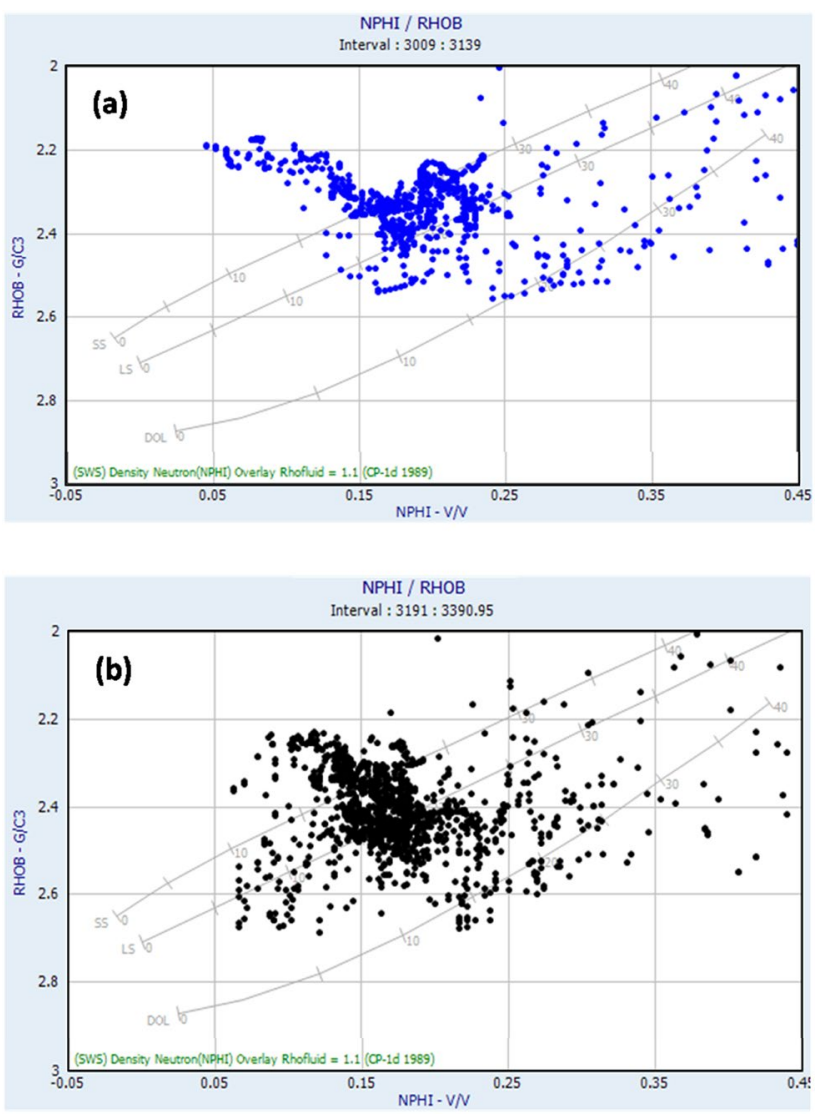

Fig. 16 Neutron-density cross-plots of the studied wells indicating different lithologies

established that the Kaimiro Formation has a good reservoir quality and has higher ability to storage capacity.

The neutron-density cross-plots have been constructed (Fig. 16). The cross-plots show that the Kaimiro Formation consist mainly of sandstone with interbedded siltstone, mudstone and carbonates (calcite). Scattering of data points along the graph indicates wide range of lithology (Jumat et al. 2018) which may be due to the density of other materials present such as silt, clay and carbonate minerals. The presence of other minerals such as clay minerals and calcite is observed within the photomicrographs (Figs. 6, 7). Clay minerals (kaolinite) and calcite cementation are observed in the petrographic study (Figs. 6c, f, 7b, c). The Kaimiro Formation is of fluvial-estuarine depositional settings with coarse-grained sediments, and good sorting supports a good reservoir quality within a formation King and Thrasher (1996). The results are in concurrence with the results obtained from this research (Table 2). 
Table 1 Well log petrophysical parameters of the Kaimiro Formation

\begin{tabular}{lllllllll}
\hline Well name & $\begin{array}{l}\text { Gross thick- } \\
\text { ness }(\mathrm{m})\end{array}$ & Net reservoir $(\mathrm{m})$ & Net pay $(\mathrm{m})$ & $\mathrm{N} / \mathrm{G}$ & $\begin{array}{l}\text { Avg. poros- } \\
\text { ity (\%) }\end{array}$ & Avg. Vcl (\%) & Avg. Sw (\%) & Avg. SHc (\%) \\
\hline Maui-7 & 130 & 36.35 & 36.35 & 0.28 & 16.3 & 36.5 & 27.7 & 72.3 \\
MB-P(8) & 199.95 & 93.65 & 93.65 & 0.468 & 14.6 & 28 & 24.2 & 75.8 \\
\hline
\end{tabular}

Cut-offs used for net pay: porosity $<10 \%, \mathrm{Vcl}<50 \%, \mathrm{Sw}<50 \%$

$A v g$. average porosity $\mathrm{Vcl}$ volume of clay, $\mathrm{Sw}$ water saturation, $S H c$ hydrocarbon saturation

Table 2 Textural figures of the selected wells of the Kaimiro Formation

\begin{tabular}{llllll}
\hline Well name & Depth $(\mathrm{m})$ & Texture & & \\
\cline { 3 - 6 } & & Grain size (phi) & $\begin{array}{l}\text { Grain size } \\
\text { (class) }\end{array}$ & Sorting (phi) & Sorting (class) \\
\hline Maui-7 & 3011.44 & $\mathrm{Tr}$ & $\mathrm{cU}$ & 0.938 & $\mathrm{MP}$ \\
& 3031.54 & 2.151 & $\mathrm{fU}$ & 0.552 & $\mathrm{MG}$ \\
Maui-A1G & 3131.82 & 0.641 & $\mathrm{cL}$ & 0.634 & $\mathrm{MG}$ \\
MB-(P)8 & 3195.35 & 1.53 & $\mathrm{~mL}$ & 0.662 & $\mathrm{MG}$ \\
& 3378.43 & 0.707 & $\mathrm{cL}$ & 0.642 & $\mathrm{MG}$ \\
Toru-1 & 3776.71 & 0.72 & $\mathrm{cL}$ & 0.470 & $\mathrm{GO}$ \\
& 3843.53 & 0.901 & $\mathrm{cL}$ & 0.496 & $\mathrm{GO}$ \\
& 3844.15 & 0.846 & $\mathrm{cL}$ & 0.719 & $\mathrm{MT}$ \\
Tui-1 & 3332.50 & 2.78 & $\mathrm{fL}$ & 0.512 & $\mathrm{MG}$ \\
& 3338.00 & 2.629 & $\mathrm{fL}$ & 0.505 & $\mathrm{MG}$ \\
& 3468.00 & 1.283 & $\mathrm{mU}$ & 0.687 & $\mathrm{MG}$ \\
& 3473.50 & 3.784 & $\mathrm{vfL}$ & 0.691 & $\mathrm{MG}$ \\
\hline
\end{tabular}

Grain size-Tr: traces, grain size classes— $c U$ : upper coarse-grained; $c L$ : lower coarse-grained, $m U$ : upper medium-grained; $m L$ : lower medium-grained; $f U$ : upper fine-grained; $f L$ : lower fine-grained; $v f L$ : lower very fine-grained, Sorting classes- $G O$ : good sorting; $M G$ : moderately good sorting; $M T$ : moderate sorting; $M P$ : moderately poor sorting

\section{Conclusions}

The reservoir characteristics and the hydrocarbon potential of the Kaimiro Formation in the Taranaki Basin have been evaluated through petrophysical study, sedimentological and petrographical descriptions and well log analysis. It is established from the petrophysical examination that the relationship between the porosity and permeability is positive and several fluid flow units are expected from the interval of interest. Excellent reservoir is expected from Maui-7, Maui-AG, MB-P(8) and Toru-1 wells which displays higher RQI, FZI and $\mathrm{r} 35$ indicating macro- to megapore spaces. Lower reservoir quality is obtained from Tui-1 well of macropores. This correlation indicates that the petrophysical parameters within the formation have a major influence on the reservoir quality of the formation. Based on the sedimentological and petrographical studies, the diagenetic features that are mostly observed are compaction, cementation, the presence of clay minerals and dissolution. Intense compaction and dissolution are noticed to enhance petrophysical parameters; however, the presence of various contacts, cementation and authigenic clay minerals is observed to reduce the reservoir properties of the formation. Nevertheless, primary and secondary porosities are mainly available as the features are observed to coexist together, thus inferring that the formation has a good reservoir quality. Lastly, qualitative and quantitative interpretations from the well log analysis indicate that the formation is a promising reservoir as all the studied wells comprise good average effective porosity values of more than $14 \%$, low average water saturation values of below $30 \%$, high average hydrocarbon saturation values of above $70 \%$ and good net pay zones. Among the studied wells, well MB- $\mathrm{P}(8)$ is the most productive well as this well has the highest average hydrocarbon saturation of $75.8 \%$, a good net pay zone of $93.65 \mathrm{~m}$ and a good average effective porosity of $14.6 \%$. The integrated reservoir characterization indicates that the Kaimiro Formation is a promising reservoir with good reservoir attributes and flow units to accommodate adequate fluid. 
Acknowledgements The authors are grateful to New Zealand Petroleum and Minerals, Ministry of Business, Innovation and Employment (MBIE), for providing the data and rock samples, as well as giving the approval for re-evaluation, interpretation and publication of the dataset. Special thanks for Mr. Ian Della Torre and Mr. Daniel Willmott for their technical assistance during the research trip to New Zealand and to AKM Eahsanul Haque for carrying the rock samples to Brunei Darussalam. Last but not least, sincere gratitude is also extended to the Universiti Brunei Darussalam for providing assistance and support in completing this research.

\section{Compliance with ethical standards}

Conflict of interest On behalf of all the co-authors, the corresponding author states that there is no conflict of interest.

Open Access This article is licensed under a Creative Commons Attribution 4.0 International License, which permits use, sharing, adaptation, distribution and reproduction in any medium or format, as long as you give appropriate credit to the original author(s) and the source, provide a link to the Creative Commons licence, and indicate if changes were made. The images or other third party material in this article are included in the article's Creative Commons licence, unless indicated otherwise in a credit line to the material. If material is not included in the article's Creative Commons licence and your intended use is not permitted by statutory regulation or exceeds the permitted use, you will need to obtain permission directly from the copyright holder. To view a copy of this licence, visit http://creativecommons.org/licenses/by/4.0/.

\section{References}

Al Areeq NM, Soliman MA, Essa MA, Al-Azazi NA (2014) Diagenesis and reservoir quality in the Lower Cretaceous Qishn sandstones from Masila oilfields in the Sayun-Masila Basin, eastern Yemen. Geol J51:405-420

Amaefule JO, Altunbay M, Tiab D, Kersey D, Keelan D (1993) Enhanced reservoir description: using core and log data to identify hydraulic (flow) units and predict permeability in uncored intervals/wells. Presented at the SPE Annual Technical Conference and Exhibition, Houston, 3-6 October. SPE 26436. https ://doi.org/10.2118/26436-MS

Baiyegunhi C, Liu K, Gwavava O (2017) Diagenesis and reservoir properties of the Permian Ecca Group sandstones and mudrocks in the Eastern Cape Province. S Afr Miner 88(7):1-26

Baur J, Sutherland R, Stern T (2014) Anomalous passive subsidence of deep-water sedimentary basins: a prearc basin example, southern New Caledonia Trough and Taranaki Basin. N Z Basin Res 26:242-268

Cade CA, Evans IJ, Bryant SL (1994) Analysis of permeability controls a new approach. Clay Miner 29:491-501

Dong PS, Shalaby MR, Islam MA (2018) Integrated reservoir characterization study of the McKee Formation, Onshore Taranaki Basin, New Zealand. Geosciences 8(4):105

Ehrenberg SN (1990) Relationship between diagenesis and reservoir quality in sandstones of the Garn Formation, Haltenbanken, mid-Norwegian continental shelf. Am Assoc Pet Geol Bull 74:1538-1558

El Sharawy MS, Nabawy BS (2019) Integration of electrofacies and hydraulic flow units to delineate reservoir quality in uncored reservoirs: a case study, Nubia Sandstone Reservoir, Gulf of Suez, Egypt. Nat Resour Res. https://doi.org/10.1007/s1105 3-018-9447-7
Higgs KE, Crouch EM, Raine JI (2017) An interdisciplinary approach to reservoir characterisation; an example from the early to middle Eocene Kaimiro Formation, Taranaki Basin, New Zealand. Mar Pet Geol 86:111-139

Jinliang Z, Ying J, Guilin D (2007) Diagenesis and Its effect on reservoir quality of Silurian Sandstones, Tabei Area, Tarim Basin, China. Pet Sci 4:1-13

Jumat N, Shalaby MR, Islam MA (2018) Integrated reservoir characterization of the Paleocene Farewell Formation, Taranaki Basin, New Zealand, using petrophysical and petrographical analysis. J Pet Explor Prod Technol 8:685-701

King P, Thrasher G (1996) Cretaceous-Cenozoic geology and petroleum systems of the Taranaki Basin, New Zealand. Institute of Geological and Nuclear Sciences Limited, New Zealand, Lower Hutt

Knox G (1982) Taranaki Basin, structural style and tectonic setting. N Z J GeolGeophys 25:125-140

Kolodzie S Jr (1980) Analysis of pore throat size and use of the Waxman-Smits equation to determine OOIP in Spindle Field, Colorado. Presented at the SPE annual technical conference and exhibition, Dallas, 21-24 September. SPE 9382. https:// doi.org/10.2118/9382-MS

Kroeger K, Funnell R, Nicol A, Fohrmann M, Bland K, King P (2013) 3D crustal heat-flow regimes at a developing active margine (Taranaki Basin, New Zealand). Tectonics 591:175-193

Laird MG, Bradshaw JD (2004) The break-up of a long-term relationship: the Creataceous separation of New Zealand from Gondwana. Gondwana Res 7(1):273-286

Levorsen AI (1967a) Geology of Petroleum. W.H. Freeman, San Fransisco

Ministry of Business, Innovation and Employment, New Zealand (2014) New Zealand Petroleum Basins 2014/2015, Revised edn. New Zealand Petroleum and Minerals, Wellington, p 105

Nabawy BS, Al-Azazi NAS (2015) Reservoir zonation and discrimination using the routine core analyses data: the upper Jurassic Sab'atayn sandstones as a case study, Sab'atayn basin, Yemen. Arab J Geosci 8(8):5511-5530. https://doi.org/10.1007/s1251 7-014-1632-3

New Zealand Petroleum and Minerals (2014) New Zealand petroleum basins

Osli LN, Yakub NY, Shalaby MR, Islam MA (2018) Log-based petrophysical analysis of the Khatatba Formation in Shoushan Basin, North Western Desert, Egypt. Geosci J 22:1015-1026

Palmer J (1985) Pre-miocene lithostratigraphy of Taranaki Basin, New Zealand. N Z J GeolGeophys 28(2):197-216

Pilaar WF, Wakefield L (1978) Structural and stratigraphic evolution of the Taranaki Basin, offshore North Island, New Zealand. Aust Pet ExplorAssoc J 18:93-101

Qadri SMT, Islam MA, Shalaby MR (2019a) Three-dimensional petrophysical modelling and volumetric analysis to model the reservoir potential of the Kupe Field, Taranaki Basin, New Zealand. Nat Resour Res. https://doi.org/10.1007/s1105 3-018-9394-3

Qadri SMT, Islam MA, Shalaby MR (2019b) Application of well $\log$ analysis to estimate the petrophysical parameters and evaluate the reservoir quality of the Lower Goru Formation, Lower Indus Basin, Pakistan. GeomechGeophys Geo-energy Georesour 5(3):271-288. https://doi.org/10.1007/s40948-019-00112-5

Rossi C, Goldstein RH, Marfil R (2000) Pore fluid evolution and quartz diagenesis in the Khatatba Formation, Western Desert, Egypt. J GeochemExplor 69-70:91-96

Rossi C, Marfil R, Ramseyer K, Permanyer A (2001) Facies-related diagenesis and multiphase siderite cementation and dissolution in the reservoir sandstones of the Khatatba Formation, Egypt's Western Desert. J Sediment Res 71:459-472 
Schlumberger (1989) Log Interpretation Principles. Schlumberger Educational Services, Midland

Schmidt V, McDonald DA (1979) The role of secondary porosity in the course of sandstone diagenesis. In: Scholle PA, Schluger RR (eds) Aspects of diagenesis. SEPM Society for Sedimentary Geology, USA, Special Publication 26, pp 175-207

Shalaby MR, Islam MA (2017) Fracture detection using conventional well logging in carbonate Matulla Formation, Geisum oil field, southern Gulf of Suez, Egypt. J Pet Explor Prod Technol 7:977989. https://doi.org/10.1007/s13202-017-0343-1

Shalaby MR, Hakimi MH, Abdullah WH (2014a) Petroleum system analysis of the Khatatba formation in the Shoushan basin, north western desert, Egypt. Arab J Geosci 7(10):4303-4320. https:// doi.org/10.1007/s12517-013-1109-9

Shalaby MR, Hakimi MH, Abdullah WH (2014b) Diagenesis in the Middle Jurassic Khatatba Formation sandstones in the Shoushan Basin, northern Western Desert, Egypt. Geol J 49(3):239-255. https://doi.org/10.1002/gj.2512

Shalaby MR, Hakimi MH, Abdullah WH, Islam MA (2016) Implications of controlling factors in evolving reservoir quality of the Khatatba Formation, Western Desert, Egypt. ScientiaBruneiana Special Issue 2016:129-146

Shalaby MR, Jumat N, Islam MA (2018) Formation MicroScanner providing better answers for carbonate secondary porosity in Alamein Dolomite Formation, NW Desert Egypt. Geosciences 8(4):118. https://doi.org/10.3390/geosciences8040118

Thrasher GP (1992) Last Cretaceous Geology of Taranaki Basin, New Zealand. PhD thesis, Victoria University of Wellington
Tiab D, Donaldson EC (2012) Petrophysics: theory and practice of measuring reservoir rock and fluid transport properties. Gulf Professional Publishing, Houston

Uruski CI, Baillie P, Stagpoole V (2003) Development of the Taranaki Basin and comparisons with the Gippsland Basin: Implications for deepwater exploration. APPEA J 43(1):185-196

Winland HD (1972) Oil accumulation in response to pore size changes, Weyburn field, Saskatchewan: Amoco Production Company Report F72-G-25 (unpublished)

Winland HD (1976) Evaluation of gas slippage and pore aperture size in carbonate and sandstone reservoirs: Amoco Production Company Report F76-G-5 (unpublished)

Worden RH, Morad S (2000) Quartz cement in oil field sandstones: a review of the critical problems. In: Worden RH, Morad S (eds) Quartz cementation in sandstones. International Association of Sedimentologists, Special Publication, 29, pp 1-20

Worden RH, Morad S (2003) Clay minerals in sandstones: controls on formation distribution and evolution. In: Worden RH, Morad S (eds) Clay mineral cement in sandstones. International Association of Sedimentologists, Special Publication, 34, pp 3-41

Publisher's Note Springer Nature remains neutral with regard to jurisdictional claims in published maps and institutional affiliations. 